\title{
Measuring and modeling energy resilience ${ }^{1}$
}

\author{
Andrea Gatto*2 Carlo Drago ${ }^{3}$
}

\begin{abstract}
Resilience is a hot topic within the international development agenda and Sustainable Development Goals. Nowadays, resilience plays a crucial role in improving the quality of life of vulnerable categories and is designed as a major strategy to face the diverse dimensions and dynamics of vulnerability. Energy results among the most relevant fields of applications of resilience policies, especially when it comes to electricity. As a multidimensional concept, energy resilience policies must relate to the dimensions of sustainability - here considered as the interplay between the economic, social, environmental and governance dimensions. Due to the complexity of the phenomenon, energy resilience can be effectively outlined making use of composite indicators techniques. This paper presents the following new results: i) energy resilience is defined and ranked, strengthening a composite indicator for both OECD and non-OECD countries; the determinants of energy resilience are investigated; ii) an innovation on the construction of the World Bank's Regulatory Indicators on Sustainable Energy is operated. Our exercise makes use of an approach based on interval data to assess the sensitivity of the measure from different specifications. For the same scope, the robustness of the ranks obtained is analyzed through an uncertainty analysis. These choices aim to enhance the soundness and the validity of the composite indicator. The methodology provides a more reliable baseline to validate the results and the conceptual assumptions undertaken. It is found that, according to the diverse theoretical frameworks and methodologies applied, some countries vary considerably both in the pillars that aggregate the variables and within the minima, the centers, and the maxima of the intervals.
\end{abstract}

Keywords: Energy resilience Energy access Energy efficiency Renewable energy Composite indicators Interval-based composite indicators

JEL classification: 013 Q01 C43 Q42 Q57

\footnotetext{
* Corresponding author.

${ }^{1}$ The paper benefited from valuable comments received from Carolina Facioni, Serenella Stasi, and participants at the 2017 Annual Conference on Well-being and Sustainability, held by the Italian Association for Studies on Quality of Life (AIQUAV). The authors are grateful for the valuable recommendations provided by Filomena Maggino, Maurizio Vichi, Anna Rita Manca, Enrico Giovannini, and attendees of the workshop and tutorial Vulnerability and Resilience: Theories, Methodologies and Applications, held at the University of Rome La Sapienza as part of the Sustainable Development Festival 2018. The authors must also thank the participants at the Joint Econometrics and Finance Seminar Series organized by the University of Aarhus, Denmark - BSS and CREATES, for their suggestions concerning the methodology, the data, and the theoretical issues. More specifically, the authors wish to thank Luca Neri, Martin Magris, Christian Bjørnskov, and Martin Paldam. The authors are also in debt to Benjamin Sovacool and Paolo Acampora for the useful advice and comments provided, and with two anonymous referees who improved the manuscript.

${ }^{2}$ Natural Resources Institute, University of Greenwich, Central Avenue, Chatham Maritime, ME4 4TB, UK. New College of the Humanities at Northeastern University, 19 Bedford Square, Fitzrovia, London WC1B 3HH, UK. Centre for Studies on Europe, Azerbaijan State University of Economics (UNEC), Azerbaijan. Email: a.gatto@greenwich.ac.uk.

3 University "Niccolò Cusano", Rome, Via Don Carlo Gnocchi 3, Italy. NCI University in London, 4 Selsdon Way Northern \& Shell London E14 9GL, UK. Email: carlo.drago@unicusano.it.
} 


\section{Introduction}

\subsection{Defining energy resilience}

Resilience has assumed a crucial role in policymaking in recent years. Resilience represents a breakthrough in the quest for improving the quality of life and wellbeing of people, especially in developing countries (Gatto, 2020). This feature results foremost for the vulnerable categories, above all rural people, women, the elderly, people with disabilities, and minorities. Sound resilience policies can promote a set of strategies to face the dimensions of vulnerability itself for the sake of sustainable development (Agovino et al., 2018; Gatto, 2018).

Resilience can be framed in the context of energy (Gatto and Drago, 2020). Energy resilience (ER) is a multidimensional concept. Therefore, in this study, energy resilience is embedded within the four dimensions of sustainability (economy, society, environment and governance), of worth to be gauged through composite indicators.

We define energy resilience as: "the ability of an energy system to retain, react, overcome and overpass perturbations caused by a shock in economic, social, environmental and institutional terms, coming from the learning capacity to adapt to change".

The studies of Martin (2012), Giovannini (2015) and JRC (2015) are pertinent to the concepts expressed. Holding the proximity between resilience and vulnerability, one should also contemplate the definition of energy vulnerability (EV). EV is defined as "the degree to which an energy system is unable to cope with selected adverse events and risks to fall into traps in economic, social, environmental and institutional terms" (Gatto and Busato, 2020). The literature emphasizes the connection existing between resilience and vulnerability (Gatto and Busato, 2020; Gnansounou, 2008), advocating the use of resilience as a proxy of vulnerability, being a driver of long-term sustainability trends. This is due to the fact that resilience affects livelihood security, exposure to risk, increasing vulnerability or adaptive capacity and hazard mitigation, fundamental factors in detecting resilience measures. On these bases, it emerges that resilience has to be taken into account when drafting energy policies aiming at tackling vulnerability.

\subsection{Gauging energy resilience: composite indicators}

Composite indicators are increasingly relevant measurement tools. The big-data era raises the need to synthesize complex phenomena and complexity by considering a multitude of relevant indicators. With this scope, composite indicators are worthy instruments to investigate determinants, formulate policy recommendations and for the public communication of the results as rankings (OECD and JRC, 2008). The output sorting from the different composite indicators can be compared between different statistical units. Furthermore, one of the principal advantages of using composite indicators is their simplicity and their capacity to be easily disseminated and described to a public of nonexperts (Becker et al., 2017).

The need for composite indicators on energy clearly arises. The World Bank (Banerjee et al., 2017) considers composite indicators to be valuable methodologies to assess the national policy and the regulatory framework, useful in striving for sustainable energy targets. The RISE - Regulatory Indicators for Sustainable Energy 2016 (Banerjee et al., 2017; International Energy Agency and World Bank, 2017) is an indicator developed by the World Bank. It is aimed at furnishing an international country-based ranking on regulatory factors related to sustainable energy. 
Relevant problems concern the subjectivity of the choices of the composite indicators which are defined by different rationale; for solving this puzzle, participatory methodologies have been proposed (Maggino and Ruviglioni, 2009). The diverse options can lead to extremely diverse indicators and outcomes. Each choice brings different results, such as for the theoretical framework that sustains the research question, the rationale behind data collection, analysis and treatment, the diverse pillar composition, the decisions regarding normalization, weighting and aggregation, the robustness analysis and the communication techniques adopted (OECD and JRC, 2008).

\subsection{Main contributions and structure of this paper}

The scope of this work is to build a composite indicator by ensuring the robustness, defensibility and usefulness of the choices in international negotiations (Nardo et al., 2005). A viable option for such an indicator is to base it on an interval of data instead of a single value. Amongst the possible choices, the use of an interval-based composite indicator in the field of sustainable energy is reputed to be a robust methodological choice to define and measure resilience. We make use of interval data to endogenize the concept of variation and uncertainty amidst the composite indicator. The emerging variation is useful in building understanding and interpreting the composite indicators: some inputs are calculated with uncertainty; elsewhere, there is a need to consider different assumptions or inputs on the construction of the composite indicator, i.e. the robustness assessment. At the same time, the interval in itself is considered a signal that there exist different performances on the underlying indicators, which combined allow to obtain the composite indicator.

Reliability - or also robustness - of the composite indicators is an additionally helpful element in the analysis of the national policies. In our work, many different solutions were assessed. To corroborate our decision, we dealt with a sensitivity analysis, as prescribed in the related literature (Saisana et al., 2005). We transform the intervals into classical data by examining the centers of the interval. In this way, we evaluate the variability associated with the interval.

Our proposal shares some theoretical points and rationale with the works reviewed. More specifically, Roege et al. (2014) foresee for resilience the capacity of a system to recover from adverse events. As in the latter, we also contemplate the necessity of gauging resilience in specific sectors with objective tools. Differently from us, for calculating energy resilience, they construct a matrix-based methodology. Conversely, we propose a composite indicator based on interval data and compare the outputs with alternative techniques and existing indexes. These research decisions were preferred as they yield a nonsubjective baseline to our results.

With respect to further studies reviewed, our proposal presents some additional differences. Albeit the similarities, as compared to other research, we stress the macroeconomic dimension of energy resilience, analyzing a vast group of countries. Differently from the latter work analyzed (Roege et al., 2014), we interpret resilience as being composed of a complex set of capacities: in our conception, a resilient system is able to retain, react, overcome and overpass a major event, as part of a wider learning capacity to adapt to change. This is an important innovation, where most of the existing contributions refer to the ability to move back to the status quo stage; instead, as recommended by Martin (2012) and the JRC (2015), we attempt to challenge the status quo. Thus, we propose to consider resilience as the capacity of bouncing forward to a further point with respect to the moment when the major event took place. As of last but not 
least peculiarity of our proposal, we operate the application of resilience to the dimensions of sustainability.

The study presents a further novelty: the interval composite indicator chosen aims at measuring specifically the interval related to the different assumptions that have been evaluated on the same composite indicator (Drago and Gatto, 2018; Drago, 2014; Moore, 1966). More specifically, this exercise exploits different weightings of the RISE, which address the different sub-components. In order to perform the different weightings by simulation, we build the diverse composite indicators starting from a range of assumptions. We eventually obtain the centers, the minima, and the maxima, and finally get the international rankings on energy resilience.

The paper is outlined as follows: the next setion (Section 2), reviews the most recent policies, regulation, and literature progress on energy resilience. Section 3 examines the data employed, focusing on the World Bank's Regulatory Indicators for Sustainable Energy data and the index developed contextually. We investigate the data collection, the choices behind the adoption of the variables and the construction of the pillars that compose our index. The fourth section (Section 4) explores the methodology. The interval data technique and the methodological procedure that allowed building the new composite indicator are scrutinized. Section 5 describes the empirical results. Here are examined the worldwide rankings, the results in terms of pillars and international trends, and the results of the minima, the centers, and the maxima of the different intervals. The outputs are checked by making use of an uncertainty analysis, which is run to corroborate the results achieved. The last section (Section 6) concludes the paper.

\section{Energy resilience: development agenda, regulation, and existing literature}

\subsection{Agenda 2030 and energy policy regulation}

Vulnerability and resilience assumed a leading role in the Agenda 2030 (UN, 2015). Some of the objectives of Sustainable Development Goals (SDGs) specifically target to fight vulnerability and enhance resilience, especially for the vulnerable categories. Some of the foremost targets are related to building social justice, adequate education, nutrition and long-term development assets for the vulnerable. The strategy includes embarking resilience and sustainable governance and reducing exposure of the vulnerable and vulnerability to climate-related extreme events, resource pauperism, and other economic, social and environmental shocks and disasters, promoting ecological targets, and innovative cities, productions and consumptions.

Energy policy has a primary role in sustainable development, being the object of a whole Goal within SDGs. SDG 7 states to: "ensure access to affordable, reliable, sustainable and modern energy for all". The goal is composed of 5 targets, 6 indicators. The prominence of the issue having emerged, the most relevant SDGs to energy resilience point at achieving universal sustainable energy targets, pushing clean resources, enhancing energy efficiency, promoting international cooperation schemes for boosting research and technology for renewables, and modern infrastructure and technology. The promotion of worldwide electricity access strategies is a priority and presents development and growth opportunities for industry and governments, of worth for renewables and energy efficiency (International Bank for Reconstruction and Development, The World Bank, 2017).

The EU benchmarks energy resilience regulation, following the US regulative production. Many major adverse events and crises have happened in the West in the last two decades. As a reaction, there has been 
produced abundant regulation on energy policy as a way to tackle these shocks and adverse incumbencies to ensure that there is not the repetition of similar occurrences.

Amongst the number of European Commission directives, in 2011 there was approved the Regulation on Wholesale Energy Market Integrity and Transparency (REMIT) (EU, 2011). This piece is paramount since it was shaped to improve the balance of the European energy markets and its transparency and tackle insider trading and market manipulation, a lesson learned from the US regulatory fiasco that led to the 2000-2001 Western power crisis (Busato and Gatto, 2019; Gnansounou, 2008). It results nowadays as a primary regulative response to face energy vulnerability. A further regulation that turned out to be pivotal for energy resilience and ecological issues was the EU Circular Economy package, approved in 2015 (see Ghisellini et al., 2016), whose action plan was launched in March 2019. The package was first applied in China. Circular Economy designs a new industrial model, capable of furnishing new solutions for energy, especially concerning waste disposal. Based on reducing, reusing and recycling, the Circular Economy package aims at accelerating the abandonment of the classic "linear" productive models (Gatto et al., 2017).

\subsection{Literature review}

Further studies analyze energy resilience through different lenses. Some works are more aligned with our scopes and contributed to shaping our theoretical framework and research question. Ghasemieh et al. (2015) investigate energy resilience with regard to the use of renewable energy in housing and energy efficiency. Sircar et al. (2013) examine energy resilience in the field of futures studies. For this scope, they propose a scenario analysis for 2050 in the UK, regarding energy and transportation. Sharifi and Yamagata (2016) review energy resilience in the cities, referring mostly to the urban studies literature. As in our proposal, McLellan et al. (2012), attach the concept of energy resilience to sustainability. They foresee a triangulation amongst resilience, sustainability and risk management to face disasters. A further paper stressing the nexus in the energy policy domain is proposed by Gnansounou and Dong (2010). In analyzing models of energy vulnerability pertaining to disturbances on the supply side, the paper distinguishes amongst models that apply or not non-resilience rationales.

He et al. $(2015,2017)$ make use of the input-output technique for testing resilience in China. They apply this method, respectively, to the energy imports and the energy-economic recovery. When it comes to analyses examining specific energy sources, energy resilience is applied to the hydrogen sector by Afgan and Veziroglu (2012). On the other hand, bioenergy is evaluated by Saha and Eckelman (2015), with the scope of furnishing a spatial cut to their findings. Although it does not target energy, another essential momentum for our analysis is the index launched by the United Nations Food and Agriculture Organization, the Resilience Index Measurement Analysis II (FAO, 2016). This methodology approaches resilience at a micro level, where the main point of the analysis is the household, considered the focal point for asset smoothing, therefore essential in boosting resilience. In RIMA II, as in our analysis, strong is the role of shocks - distinguished in idiosyncratic and covariate for which a method is built. A contribution that shares even more similarities with respects to our study is that proposed by Roege et al. (2014). They first implement a theoretical baseline to define and discuss energy resilience. Therefore, they build a metric to compute energy resilience.

Resilience is strictly linked with ecology. Some works inspected the ecological dimension embedded in resilience. Basing himself on Holling (1973), who defined ecological resilience as "the amount of 
disturbance that an ecosystem could withstand without changing self-organized processes and structures", Gunderson (2000) attributes to resilience the main properties of being based on stability and adaptive capacity, a concept that is contemplated in our work as well. Conversely, engineering resilience is conceived as return time resilience, being a resilient system characterized by the presence of either single or multiple equilibria (Holling, 1996). Perrings (2006) attributes a major role to ecological resilience in shaping forthcoming global economic and development trends. Brand (2009) investigates the role of natural capital, connecting ecological resilience with sustainable development. In this framework, ecological resilience can contribute by targeting natural capital attributes that are renewable, driven by "ecological criticality". According to Derissen et al. (2011), resilience results are independent from sustainability, and are attached to ecological-economic systems. On the other hand, the interconnectedness amongst these factors and sustainability derives from the property of sustainability stemming from intergenerational justice, provided that human wellbeing relies on natural capital.

Resilience can be adopted as well for configuring economic systems, being specially of value for the energy sector. Such an application has been presented in the field of energy transition, and more particularly for converting the German energy system towards renewables (Strunz, 2014). This new model implies deep transformations in the economy, technology and politics, paramount fields in transition economies and rentier states (Sadik-Zada, 2016).

\section{Data}

\subsection{Data collection}

The dataset employed was collected from the RISE. The aim of the RISE is to provide an assessment of the different policy and regulatory support for the pillars considered, namely: access to modern energy, energy efficiency and renewable efficiency-related energy. In particular, we consider the three components of the composite indicator: Energy Access, Energy Efficiency and Renewable Energy. The source is the World Bank, 2019 (see Banerjee et al., 2017). Each different component is expressed as: Energy Access, Energy Efficiency and Renewable Energy. We define a component as a specific part which can be combined with the other for constructing the composite indicator. In order to construct the RISE indicator, the different components analysed are equally weighted to obtain the overall score.

\subsection{Data selection: the indicators}

The chosen database examines the national policies and regulations in the energy sector. The variable sources come from the Sustainable Energy for All (SEforAll) project; namely, data is collected by the WB Group, ESMAP - Energy Sector Management Assistance Program, and CIF - Climate Investment Funds. The dataset consists of a cross-section for 2016. It is made up of 27 indicators and 111 countries, offering a representation of $96 \%$ of the world population (Banerjee et al., 2017; International Energy Agency and World Bank, 2017).

We define as pillar a component of a composite indicator. Each pillar is characterized by different subpillars which combined return the pillar. The SEforAll initiative contemplates three pillars: A) Energy Access, constructed on eight sub-pillars; B) Energy Efficiency, made up of twelve sub-pillars; C) Renewable Energy, 
composed of seven sub-pillars. We chose to take into account the same structure and variables proposed by the RISE.

The data examined show no missing values and no relevant outliers. At the same time, we standardized the indicators before proceeding with the construction of the composite indicator. The dataset employed does not present any problems with missing observations and data completeness. Thus, all observations were present and taken into account. We define our composite indicator the GERI, Global Energy Resilience Index.

Table 1 below sketches the structure and the variables that compose the GERI composite indicator.

Table 1 - Pillars and sub-pillars, GERI

\section{GLOBAL ENERGY RESILIENCE INDEX (GERI)}

\begin{tabular}{|c|c|c|}
\hline Energy Access & Energy Efficiency & Renewable Energy \\
\hline $\begin{array}{l}\text { Existence and monitoring of officially } \\
\text { approved electrification plan }\end{array}$ & National energy efficiency planning & $\begin{array}{c}\text { Legal framework for renewable } \\
\text { energy }\end{array}$ \\
\hline $\begin{array}{l}\text { Scope of officially approved } \\
\text { electrification plan }\end{array}$ & Energy efficiency entities & $\begin{array}{l}\text { Planning for renewable energy } \\
\text { expansion }\end{array}$ \\
\hline Framework for grid electrification & $\begin{array}{l}\text { Information provided to consumers } \\
\text { about electricity usage }\end{array}$ & $\begin{array}{l}\text { Incentives and regulatory support for } \\
\text { renewable energy }\end{array}$ \\
\hline Framework for minigrids & $\begin{array}{l}\text { Incentives from electricity rate } \\
\text { structures }\end{array}$ & $\begin{array}{l}\text { Attributes of financial and regulatory } \\
\text { incentives }\end{array}$ \\
\hline Framework for stand-alone systems & $\begin{array}{l}\text { Incentives \& mandates: large } \\
\text { consumers }\end{array}$ & Network connection and pricing \\
\hline Consumer affordability of electricity & Incentives \& mandates: public sector & Counterparty risk \\
\hline Utility Transparency and Monitoring & Incentives \& mandates: utilities & \multirow{6}{*}{ Carbon pricing and monitoring } \\
\hline \multirow{5}{*}{ Utility Creditworthiness } & $\begin{array}{l}\text { Financing mechanisms for energy } \\
\text { efficiency }\end{array}$ & \\
\hline & $\begin{array}{l}\text { Minimum energy efficiency } \\
\text { performance standards }\end{array}$ & \\
\hline & Energy labeling systems & \\
\hline & Building energy codes & \\
\hline & Carbon Pricing & \\
\hline
\end{tabular}




\section{Methodology}

\subsection{Interval-based composite indicators}

The literature stresses the necessity of methodological robustness for building reliable composite indicators (Luzzati and Gucciardi, 2015; Agovino et al., 2018). Following Drago and Gatto (2018), Drago (2014) and Moore (1966), an interval-based composite indicator is constructed, evaluating the different assumptions relative to the composite indicator spectrum.

In this exercise, we run a Monte-Carlo Simulation in which we assess different weighting schemes and return the final composite indicator obtained. Each weight for each component is generated by a uniform distribution. Each weight is obtained as a proportion of the total, i.e. the sum of the three generated values. The sum of the three weights is 1 . Each different weighting scheme for the single simulation determines a single value for the composite indicator and a single rank. We repeat the procedure 10,000 times. Then, we construct different intervals by evaluating all the different scenarios calculated. At the end of the different computations of the indicator, we compare the different interval data obtained by the different statistical units. We obtain three rankings: the first is related to the center (which is computed by an average of the minimum and the maximum). The second ranking regards the minimum, whilst the third is connected with the maximum. It is also possible to examine the different intervals as new types of data. This would mean to consider these new composite indicators using interval algebra (Gioia and Lauro, 2005) as international benchmarks.

\subsection{Methodological steps}

We first interpret the positive or negative direction that the variables take towards energy resilience. We attribute:

- "+": if the variable contributes to making a country more resilient;

- "-": for the variables that contribute to a country being less resilient.

Thus, we work on the normalized values on a scale of 0-100 coming from the WB RISE database. No data cleaning procedures were necessary, and no missing data were present. We then proceed to the interpretation of the sub-pillars. After weighting through equal-weight calculation, we reduce the dimensions of our indicator: we run the first aggregation from 27 sub-pillars to 3 pillars, and the second aggregation from 3 pillars to the composite indicator. A linear aggregation is run. From the Monte-Carlo Simulation we obtain our composite indicator, i.e. the GERI. Therefore, we analyze whether the ranks obtained by the centers on our indicator tend to confirm the results obtained by the original indicator. It is important to note that the GERI already takes into account the variability of the outcomes due to the Monte-Carlo Simulation performed. For this aim, we compare our results with the WB RISE outputs.

It should be said that one of the methodological added values provided by our interval data indicator is the capacity of endogenizing the different assumptions of the construction of the composite indicator, which could otherwise be subjective. 


\subsection{Modeling interval-based composite indicators for energy resilience}

For constructing the interval-based composite indicator, we start by considering a set of outputs obtained from different weighting schemes as inputs $i$.

We have:

$$
i=1,2, \ldots, I
$$

Thus, we obtain different composite indicators $Y_{i}^{c}$ such that:

$$
Y_{1}^{c}, Y_{2}^{c}, \ldots, Y_{I}^{c}
$$

(1) will sort out from the inputs and the weighting schemes on each composite indicator. We define the interval-based composite indicator according to the set of indicators computed.

We will get:

$\underline{Y_{i}}$ as the lower bound (the minimum), where we define $\overline{Y_{i}}$ as the upper bound (the maximum).

$$
\left.I[Y]^{c}=\underline{\left[Y_{i}^{c}\right.}, \overline{Y_{i}^{c}}\right]
$$

The data based on a single value can be interpreted to be cases of an interval with no variation.

We proceed by examining the different relevant elements which allow comparing the different interval data, that in this exercise are the centers (midpoints) of the interval. The resulting computation of the interval center will be:

$$
Y_{\text {center }, i}^{c}=\frac{1}{2}\left(\underline{Y_{i}^{c}}+\overline{Y_{i}^{c}}\right)
$$

The center is the final value of our interval-based composite indicator and can be compared between the different countries. We motivate the use of the centers, the minima and the maxima with the scope of reaching a range of plausible values on the composite indicator. The sensitivity of the results can be measured by analyzing the maxima and the minima and their range. The results allow working with a more 
reliable composite indicator based on an interval instead of a single value. This permits to handle and interpret different rankings for the minima, the maxima and the centers.

A diagnostic analysis is performed by comparing the interval-based composite indicator on the centers (which are derived from the minima and the maxima) to the existing composite indicator. The sensitivity analysis is acquired by assessing the different weight assumptions on the composite indicators computed. For each simulation, one single weighting scheme is sampled from a uniform distribution and a single weighting is derived. The procedure is repeated through 10,000 iterations, and the end we obtain the minima and the maxima of the composite indicator scores. The centers, the minima and the maxima are ranked differently.

Higher ranges might indicate relevant differences between the performances on every single component of the composite indicator, potentially signaling a decreased reliability of the composite indicator due to the observed differences between the minima and the maxima.

Appendix A sketches step-by-step the whole procedure adopted.

\section{Empirical results}

\subsection{Rankings on the centers, the minima, and the maxima}

The results pertain to the different rankings drawn by the procedure run. In particular, for each different scenario, we are able to get the minimum, the maximum and the center. The sorting result is comparable to our analyses with the outputs emerging from the RISE composite indicator.

Table 2 - Energy resilience: best performers and their interval scores

\begin{tabular}{|c|c|c|c|}
\hline Country & Minimum & Maximum & 92.29 \\
\hline Denmark & 85.02 & 99.56 & 90.05 \\
\hline Netherlands & 80.60 & 99.49 & 89.00 \\
\hline Germany & 79.27 & 98.74 & 88.70 \\
\hline United Kingdom & 79.36 & 98.04 & 88.17 \\
\hline Switzerland & 76.87 & 99.48 & 86.58 \\
\hline Czech Republic & 75.92 & 97.24 & 84.40 \\
\hline Greece & 76.55 & 92.24 & 84.40 \\
\hline Canada & 70.85 & 97.94 & 83.44 \\
\hline Sweden & 71.11 & 95.76 & 82.03 \\
\hline United States & 67.61 & 96.46 & 80.64 \\
\hline France & 65.83 & 95.45 & 80.08 \\
\hline Italy & 60.76 & 99.40 & 79.65 \\
\hline Finland & 61.60 & 97.69 & 79.08 \\
\hline Spain & 65.10 & 93.06 & 77.45 \\
\hline Belgium & 61.00 & 93.91 & 75.21 \\
\hline Austria & 57.61 & 92.81 & 74.35 \\
\hline Poland & 49.78 & 98.92 & 74.14 \\
\hline China & 52.52 & 93.76 & \\
\hline
\end{tabular}




\begin{tabular}{|c|c|l|l|}
\hline Kazakhstan & 56.01 & 91.61 & 73.81 \\
\hline Japan & 50.55 & 97.00 & 73.77 \\
\hline Australia & 54.77 & 92.09 & 73.43 \\
\hline Romania & 53.56 & 92.29 & 72.93 \\
\hline Turkey & 55.35 & 90.33 & 72.84 \\
\hline Mexico & 57.89 & 86.46 & 72.12 \\
\hline Korea, Rep. & 45.99 & 90.53 & 68.26 \\
\hline Pakistan & 32.80 & 99.45 & 66.13 \\
\hline Chile & 32.91 & 98.55 & 65.73 \\
\hline South Africa & 31.53 & 93.37 & 62.45 \\
\hline United Arab Emirates & 30.19 & 93.76 & 61.98 \\
\hline Jordan & 32.89 & 90.15 & 61.52 \\
\hline Brazil & 31.95 & 90.61 & 61.28 \\
\hline Malaysia & 29.22 & 90.80 & 60.01 \\
\hline India & 30.29 & 89.03 & 59.66 \\
\hline Dominican Republic & 29.31 & 89.20 & 59.26 \\
\hline Kenya & 27.57 & 90.64 & 59.10 \\
\hline
\end{tabular}

Table 2 above represents the 35 best-performing countries. These countries are those which possess the higher center relatively to the GERI.

We sketch the lower bounds, the upper bounds and the centers. From this ranking, we can observe a variation within the three sets of values. Some countries vary greatly. This is the case of Italy - respectively: 60.76, 99.40, 80.08 -, Poland -49.78, 98.92, 74.35 -, and China - 54.52, 93.76, 74.14. These are some of the countries displaying some of the greatest ranges in the values of the minima, maxima and centers of interval data for energy resilience. The minima and the maxima contribute to the creation of the final score based on the center of the interval. These are at the same time relevant because they represent the maximum and the minimum values which can be obtained from the composite indicator. The final results for the indicator constructed are more reliable if one contemplates the ranges of the same composite indicator.

For some countries displaying a higher range, the outputs turn out to be less reliable; the cases of China and Denmark can be taken as benchmarks (see Table 2 below). In these cases, the policy implications need to be evaluated more cautiously. In the presence of a higher range of the interval composite indicator, the policymaking should be addressed to assess the resulting weak points, and future policies should contemplate improvements in the final performance in this specific direction.

We examined differently the rankings resulting from the minima, the maxima and the ranges computed. One may observe that the rankings on the minima and the maxima tend, in general, to confirm the rankings on the centers. An important exception is represented by Japan, which loses comparatively four positions for minima and gains three positions with regards to maxima. Similarly, Italy gains some positions for maxima, pointing out its potential to perform well. On the other hand, some countries show a higher range. In policy terms, it is possible to assert that higher range differences often indicate a lower energy resilience.

It is possible to compare the results of the GERI and the RISE. Examining Table 2, we can observe that in the majority of cases the results do not differ significantly. For instance, Denmark is the first in both approaches. In the first 10 places, $70 \%$ of the countries remain in position even if changing places. Amongst 
GERI top ranks, the Netherlands, Germany and the United Kingdom improve their positions. Italy, France, and Romania are not in the group of the GERI top 10, whilst they appear in the RISE top 10. Even though losing eight positions, the United States remains in the top 10. These differences show that, overall, the GERI confirms the results of the RISE, but emphasizes the variability and the range of the different performances and therefore the higher and the lower energy resilience, as for the highest ranks case.

\subsection{Results for GERI pillars}

Figure 1 above sketches the results obtained by the twelve best and the twelve worst performers for GERI, differentiating the scores according to the three pillars computed in the GERI. As it is possible to deduct, for some countries the results vary dramatically amongst pillars. This is the case of Italy, one of the best performers: Italy ranks rather low in the first pillar (energy access) as compared to the second pillar (energy efficiency); in terms of renewable energy (third pillar), Italy performs well, even if other countries obtain higher scores. The performances of some countries that rank poorly - e.g. Zimbabwe, Angola or Vanuatuare in line with these results: these countries obtain extremely poor results in terms of energy access, whilst they have more encouraging scores when it comes to renewable energy and, above all, energy efficiency. Conversely, some other countries are more balanced in the three pillars ranks, for example Denmark and Greece.

This stylized fact applies particularly to the least resilient countries, that in our exercise - apart from Bahrain - are all developing/least developed countries. The best performers also show smaller variations amongst the pillars.

Figure 1 -GERI: 12 TOP, 12 WORST (each bar is proportional to the minima, the centers, and the maxima)

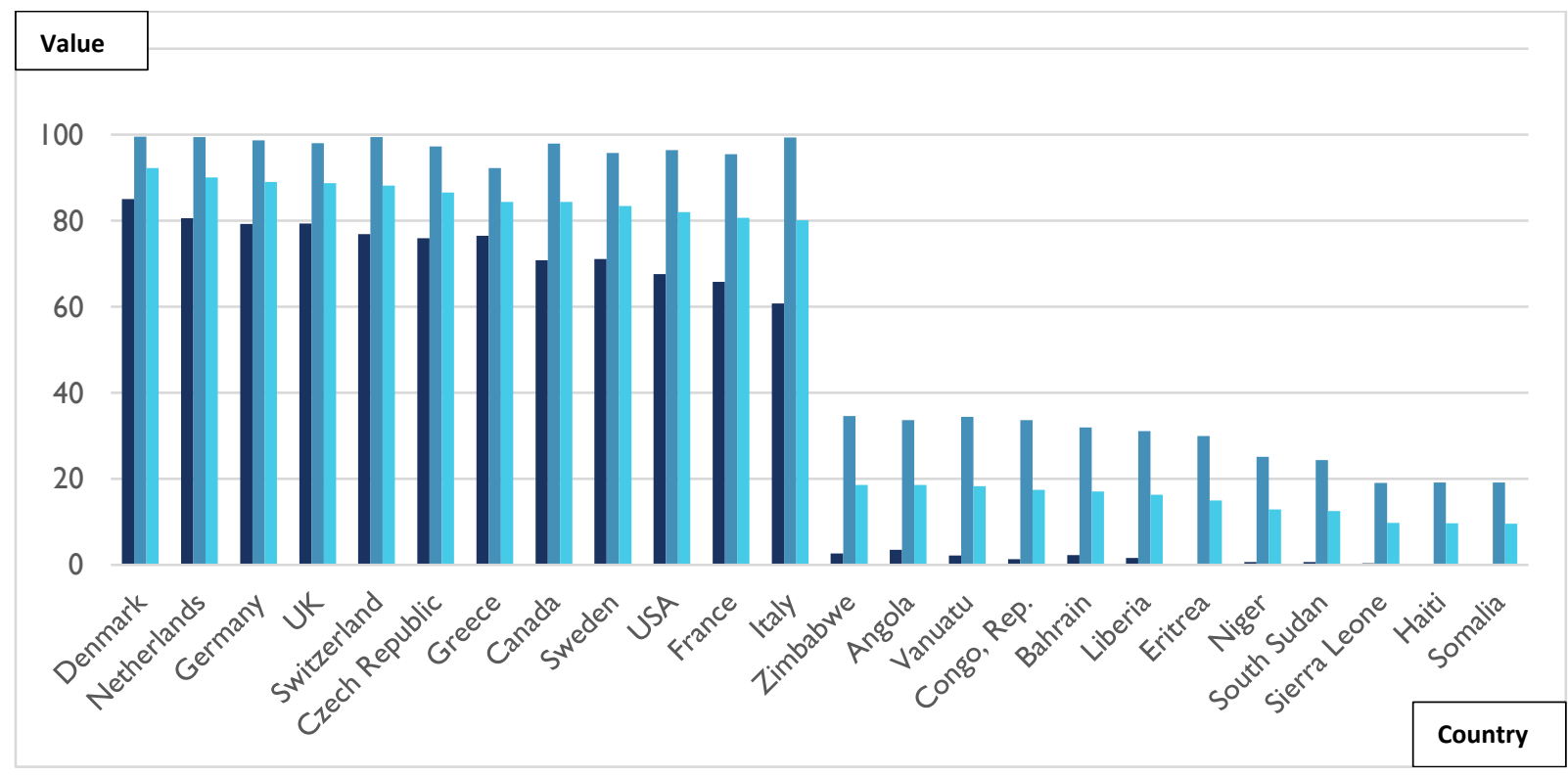

\subsection{GERI geographical appraisal}


Another important dynamic element to be caught is spatial performance. Figure 2 above represents in a map the worldwide national performances in terms of energy resilience. It is possible to appreciate that the vast majority of the world population is covered and mapped. We can also observe that, regionally, the most resilient regions are the wealthiest - North America, Europe, and Oceania. On the other hand, Latin America displays generally average/fair results. Central America varies according to the country analyzed. Asia also varies extensively: East Asia performs well - especially China and Japan -, and the other subregions rank middle-low; some exceptions exist - e.g. Kazakhstan, displaying a good energy resilience. Most of the countries of North Africa and the Middle East show average scores, but Turkey stands out for its good results. Our dataset lacks observations for some of these countries. The sub-Saharan countries are generally the least energy resilient with a few exceptions - above all South Africa.

\section{Figure 2-GERI: map}
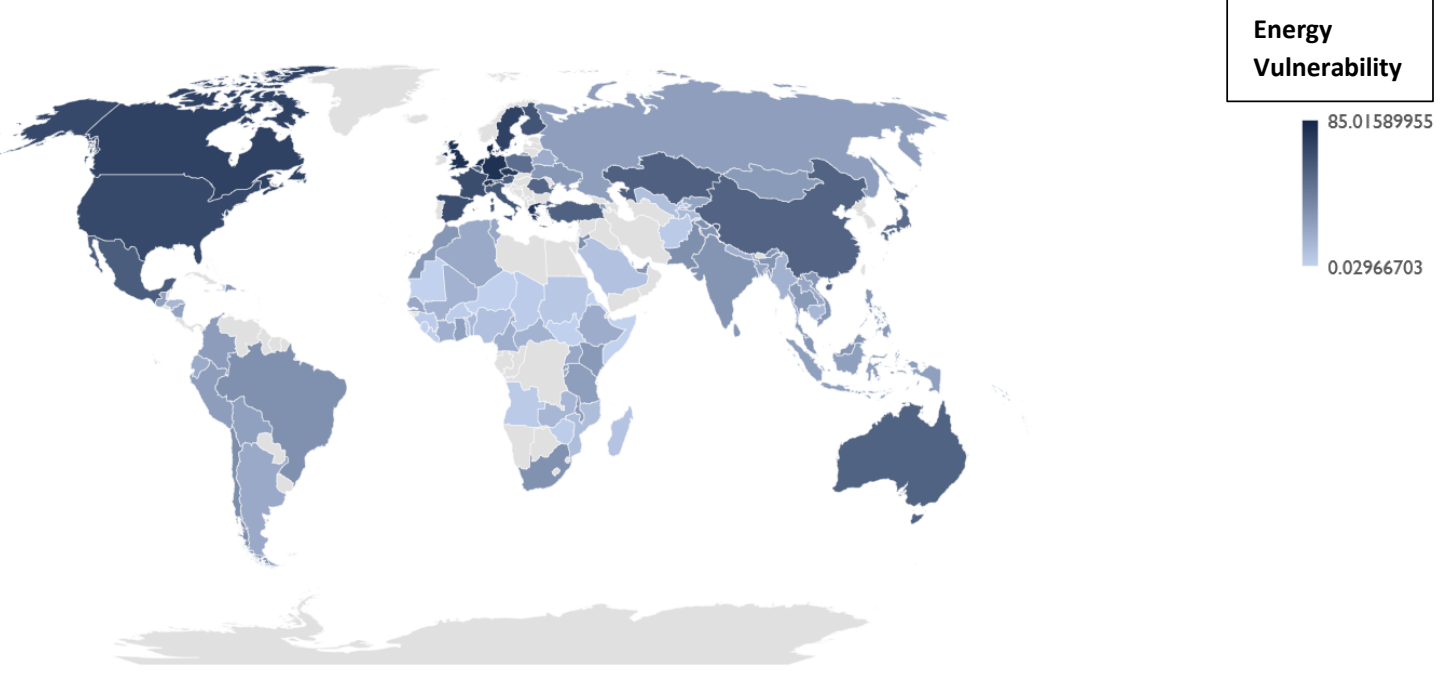

\subsection{Plotting the centers, the minima and the maxima}

Fig. 3 below plots the worldwide minima, the centers, and the maxima. We can observe a broad variance for the countries displaying average performances. Conversely, most of the countries which show a lower energy resilience, display a minor range. The relevant reason to determine the range is the correlation between the different variables. Where the correlation is higher and the value is high, the center, the upper and the lower bounds tend to grow; where, on the contrary, the ranges grow, there is a lower correlation or no correlation at all. Five different groups are represented in the rankings. In particular, the trend of the positions of the minima, the centers and the maxima are shown. It is possible to examine the rankings ranging 1-25, 26-57, 58-80, 80-100, and greater than 101. Each group is characterized by a similar level of minima, centers and maxima. It is possible to observe that the first groups (ranks 1-25) show a lower vulnerability and higher robustness than other groups, intended as a lower range between the minima and maxima. The conclusion we draw is related to the existence of 5 different levels in the performance of the indicator which can be internationally achieved and can be considered as a policy target. It is possible to remark that the first 24 countries display a higher energy resilience because the correlation between the different indicators allows to better manage external shocks. One can understand that the robustness of the different results due to the randomization of the composite indicator can be useful in measuring energy resilience. 
Figure 3-GERI - interval composite indicator: visualizing maxima, centers and minima.

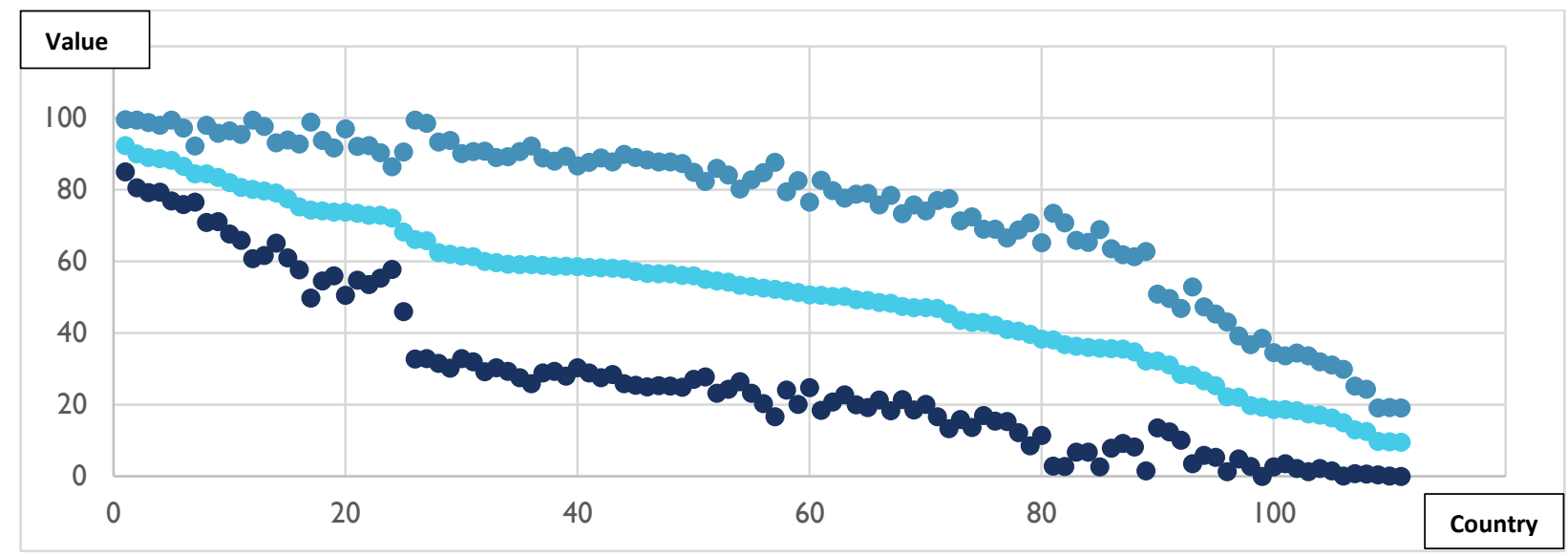

\section{Conclusions}

This investigation originated from the need to define and measure energy resilience within the energydevelopment policy framework. Energy resilience is a hot topic in the scientific literature. Though existing works focus on other aspects of energy resilience, this work attempted to contribute to the existing literature, trying to provide theoretical, policy and methodological novelties.

Energy resilience became a focal point to be addressed by the development agenda. This fact is confirmed by the inclusion of several resilience and energy targets into the Agenda 2030 (UN, 2015). The Western energy shocks and the regulatory proliferation which have occurred in the last twenty years confirm that regulation is a starting point to analyze and govern energy resilience.

In terms of theory and concepts, the need to define energy resilience became clear. The work presented is in line with an increasing part of the literature, attempting to challenge the status quo to which the classical definitions of resilience are attached. In order to corroborate the theoretical framework, this study proposed to measure energy resilience within sustainable development and regulatory attributes. For this scope, we opted for the composite indicators, a good fit to describe complex phenomena referring to sustainability variables.

In our analysis, we employed interval data. The use of this technique is a methodological choice motivated by the increase in objectivity that it pledges with respect to subjective methods. The robustness of the technique is checked and confirms the goodness-of-fit with regards to our tests. The results are in line with the benchmark indicator we examined, i.e. the Regulatory Indicators for Sustainable Energy - RISE published by the World Bank. Though it should be noted that the results differ somewhat: in several cases e.g. Italy -, the variability in resilience is evident.

The advantage of using an interval-based composite indicator lies in the fact that we are making use of a robust version of the original composite indicator, from which we explicitly utilize the methodological baseline (i.e. weight distribution). The center is not based on a single assumption (i.e. equal weighting), but on a Monte-Carlo Simulation, which simultaneously considers many different outputs. Thus, the results are 
less subjective than simply choosing a single set of assumptions. The center is the most plausible value it is possible to obtain and therefore is preferred for this exercise, where the minima and the maxima are the extreme values which can be obtained and assessed for further policy analyses.

The empirical results emerging from our methodological choices emphasize the importance of energy vulnerability for resilience: we account for a more robust and objective criterion, capturing a dynamic rationale. Our index does not focalize on the static picture - the status quo -, thus allowing us to represent the property of resilience of bouncing forward, overcoming, or learning capacity to adapt to change, as was our intention. This is a consequence of the wide range of information provided by the interval data. These facts connect with the theoretical framework designed, and reply to the international community, regulatory, and the scientific call. All these facts pave the way to strengthening and motivating the centrality of energy resilience in society.

The information for resilience policies is twofold: information related to the center, which is the main result; whilst the second is related to a possible use of the indicator. Thus, analyzing the minima and the maxima, we can deduce whether the policies need to be finalized to improve single specific indicators or not (higher the range between minima and maxima, more relevant to identify the weak points for every single country). The minima and the maxima of the intervalbased composite indicator can lead to analyze extreme scenarios in the construction of the indicator. In terms of economic policymaking, the minima and the maxima can lead to changes in energy policies, since they allow to identify situations in which the weak indicators are particularly relevant. Higher ranges can show a situation in which the countries tend to perform well for some indicators and worse for others. Thus, the energy policies should be oriented to improve the less performing indicators. In this sense, higher ranges can be a signal of alert.

Some further economic intuitions result. Analyzing energy resilience, GDP is related to renewable resources, and broadly to energy resilience, whereas it has been demonstrated that GDP is not a leading driver for energy vulnerability (Gatto and Busato, 2020). Another stylized fact is that the regulatory framework and the development agenda turn out to be crucial in shaping sound energy resilience policies. Due to their tightness, a further conclusion is that energy vulnerability highlights to be fundamental to shape resilience policies. The very key to understanding the resilience of an energy policy is to look at and study the rankings that we have provided in our research. We attempted to give policymakers the keys to spot the weaknesses in their own energy policies.

Exploring the study limitations, a caveat emerges. Besides the first center-based analysis on energy resilience, one should examine the country resilience variability as well. High variability in the results may signal a presumable lack of resilience with regard to specific pillars/sub-pillars due to high sensitivity of the outputs. This is the case of Italy, which albeit a good overall performer, presents a high variability in the interval data on energy resilience. This outcome is connected with the weak performance of Italy in some pillars with respect to the high scores displayed in some other pillars. For this reason, in the cases of high variability of the results, it is recommended to proceed more cautiously, especially in terms of policymaking, as the high variability is a potential signal of specific low resilience performances, even in resilient countries. This is why, besides the main index based on the centers, we recommend to attentively observe the variation of the results, as they are a real alerter for possible issues. We keep open the possibility of building specific composite indicators for future research.

In this context, future research might also include the examination of univariate analysis to discriminate top from worst performers and the countries might also be divided according to the pillars. 


\section{References}

Afgan, N., Veziroglu, A., 2012. Sustainable resilience of hydrogen energy system. Int. J. Hydrog. Energy 37 (7), 5461-5467.

Agovino, M., Cerciello, M., Gatto, A., 2018. Policy efficiency in the field of food sustainability. The adjusted food agriculture and nutrition index. J. Environ. Manag. 218, 220-233.

Banerjee, S.G., Moreno, F.A., Sinton, J., Primiani, T., Seong, J., 2017. Regulatory Indicators for Sustainable Energy (No. 26099). The World Bank.

Becker, W., Saisana, M., Paruolo, P., Vandecasteele, I., 2017. Weights and importance in composite indicators: closing the gap. Ecol. Indic. 80, 12-22.

Brand, F., 2009. Critical natural capital revisited: ecological resilience and sustainable development. Ecol. Econ. 68 (3), 605-612.

Busato, F., Gatto, A., 2019. Evidenze empiriche dai prezzi elettrici durante la crisi energetica californiana. Cattura del regolatore nel caso Enron? Moneta \& Credito 72 (285), 29.

Derissen, S., Quaas, M.F., Baumgärtner, S., 2011. The relationship between resilience and sustainability of ecological-economic systems. Ecol. Econ. 70 (6), 1121-1128.

Drago, C., 2014. Interval based composite indicators November 2014 conference: Conference of European Statistics Stakeholders, Rome. Work available on SSRN.

https://papers.ssrn.com/sol3/papers.cfm?abstract_id=3026021.

Drago, C., Gatto, A., 2018. A robust approach to composite indicators exploiting interval data: the intervalvalued global gender gap index (IGGGI). In: IPAZIA Workshop on Gender Issues. Springer, Cham, pp. 103114.

EU, 2011. Regulation (EU) no. 1227/2011 of the European Parliament and of the Council of 25 October 2011 on wholesale energy market integrity and transparency (REMIT). Off. J. Eur. Union L326, 1-16 (December 08, 2011).

FAO, 2016. Resilience Index Measurement and Analysis - RIMA II.

Gatto, A., 2018. Historical roots of microcredit and usury: the role of Monti di Pietà in Italy and in the kingdom of Naples in XV-XX centuries. J. Int. Dev. 30 (5), 911-914.

Gatto, A., 2020. A pluralistic approach to economic and business sustainability: A critical meta-synthesis of foundations, metrics, and evidence of human and local development. Corp. Soc. Responsib. Environ. Manag. 1-15. https://doi.org/10.1002/csr.1912.

Gatto, A., Busato, F., 2020. Energy vulnerability around the world: the global energy vulnerability index (GEVI). J. Clean. Prod. https://doi.org/10.1016/j.jclepro.2019.118691.

Gatto, A., Drago, C., 2020. A taxonomy of energy resilience. Energy Policy 136111007.

Gatto, A., Ferrari, M., Sadik-Zada, E.R., 2017. Is waste-to-energy an effective strategy to increase the resource efficiency of the economy? A Panel Data Approach to Circular Economy in EU. In: AIQUAV 2017 Associazione Italiana per Gli Studi Sulla Qualita Della Vita. 
Ghasemieh, H., Haverkort, B.R., Jongerden, M.R., Remke, A., 2015, June. Energy resilience modelling for smart houses. In: Dependable Systems and Networks (DSN), 2015 45th Annual IEEE/IFIP International Conference on. IEEE, pp. 275-286.

Ghisellini, P., Cialani, C., Ulgiati, S., 2016. A review on circular economy: the expected transition to a balanced interplay of environmental and economic systems. J. Clean. Prod. 114, 11-32.

Gioia, F., Lauro, C.N., 2005. Basic statistical methods for interval data. Statistica applicata 17 (1), 75-104.

Giovannini, E., 2015. Measuring Resilience to Design Innovation Policies. Publications Office of the European Union, Luxembourg (2015 (C) European Union, 2015).

Gnansounou, E., 2008. Assessing the energy vulnerability: case of industrialised countries. Energy Policy 36 (10), 3734-3744.

Gnansounou, E., Dong, J., 2010. Vulnerability of the economy to the potential disturbances of energy supply: a logic-based model with application to the case of China. Energy Policy 38 (6), 2846-2857.

Gunderson, L.H., 2000. Resilience in theory and practice. Annu. Rev. Ecol. Syst. 31 (1), 425-439.

He, P., Ng, T.S., Su, B., 2015. Energy import resilience with input-output linear programming models. Energy Econ. 50, 215-226.

He, P., Ng, T.S., Su, B., 2017. Energy-economic recovery resilience with input-output linear programming models. Energy Econ. 68, 177-191.

Holling, C.S., 1973. Resilience and stability of ecological systems. Annu. Rev. Ecol. Syst. 4 (1), 1-23.

Holling, C.S., 1996. Engineering resilience versus ecological resilience. Engineering within ecological constraints 31 (1996), 32.

International Bank for Reconstruction and Development, The World Bank, 2017. State of Electricity Access Report.

International Energy Agency and World Bank, 2017. Sustainable Energy for All 2017- Progress toward Sustainable Energy. World Bank, Washington DC.

JRC, 2015. The Challenge of Resilience in a Globalized World. Publications Office of the European Union, Luxembourg (2015 @ European Union, 2015).

Luzzati, T., Gucciardi, G., 2015. A non-simplistic approach to composite indicators and rankings: an illustration by comparing the sustainability of the EU countries. Ecol. Econ. 113, 25-38.

Maggino, F., Ruviglioni, E., 2009. Obtaining weights: From objective to subjective approaches in view of more participative methods in the construction of composite indicators. In: Proceedings NTTS: New Techniques and Technologies for Statistics, pp. 37-46.

Martin, R., 2012. Regional economic resilience, hysteresis and recessionary shocks. J. Econ. Geogr. 12 (1), $1-32$.

McLellan, B., Zhang, Q., Farzaneh, H., Utama, N.A., Ishihara, K.N., 2012. Resilience, sustainability and risk management: a focus on energy. Challenges 3 (2), 153-182. 
Moore, R.E., 1966. Interval Analysis. 4 Prentice-Hall, Englewood Cliffs, NJ.

Nardo, M., Saisana, M., Saltelli, A., Tarantola, S., 2005. Tools for composite indicators building. European Comission, Ispra 15, 19-20.

OECD \& Joint Research Centre, 2008. Handbook on Constructing Composite Indicators: Methodology and User Guide. OECD, Paris.

Perrings, C., 2006. Resilience and sustainable development. Environ. Dev. Econ. 11 (4), 417-427.

Roege, P.E., Collier, Z.A., Mancillas, J., McDonagh, J.A., Linkov, I., 2014. Metrics for energy resilience. Energy Policy 72, 249-256.

Sadik-Zada, E.R., 2016. Oil Abundance and Economic Growth. 70 Logos Verlag Berlin GmbH.

Saha, M., Eckelman, M.J., 2015. Geospatial assessment of potential bioenergy crop production on urban marginal land. Appl. Energy 159, 540-547.

Saisana, M., Saltelli, A., Tarantola, S., 2005. Uncertainty and sensitivity analysis techniques as tools for the quality assessment of composite indicators. Journal of the Royal Statistical Society: Series A (Statistics in Society) 168 (2), 307-323.

Sharifi, A., Yamagata, Y., 2016. Principles and criteria for assessing urban energy resilience: a literature review. Renew. Sust. Energ. Rev. 60, 1654-1677.

Sircar, I., Sage, D., Goodier, C., Fussey, P., Dainty, A., 2013. Constructing resilient futures: integrating UK multi-stakeholder transport and energy resilience for 2050. Futures 49, 49-63.

Strunz, S., 2014. The German energy transition as a regime shift. Ecol. Econ. 100, 150-158.

United Nations, 2015. Transforming our World: The 2030 Agenda for Sustainable Development. UN, RES/70/1 (2015). 
Appendix A - Interval-based composite indicator step-by-step

Figure 4 - GERI: The methodological steps

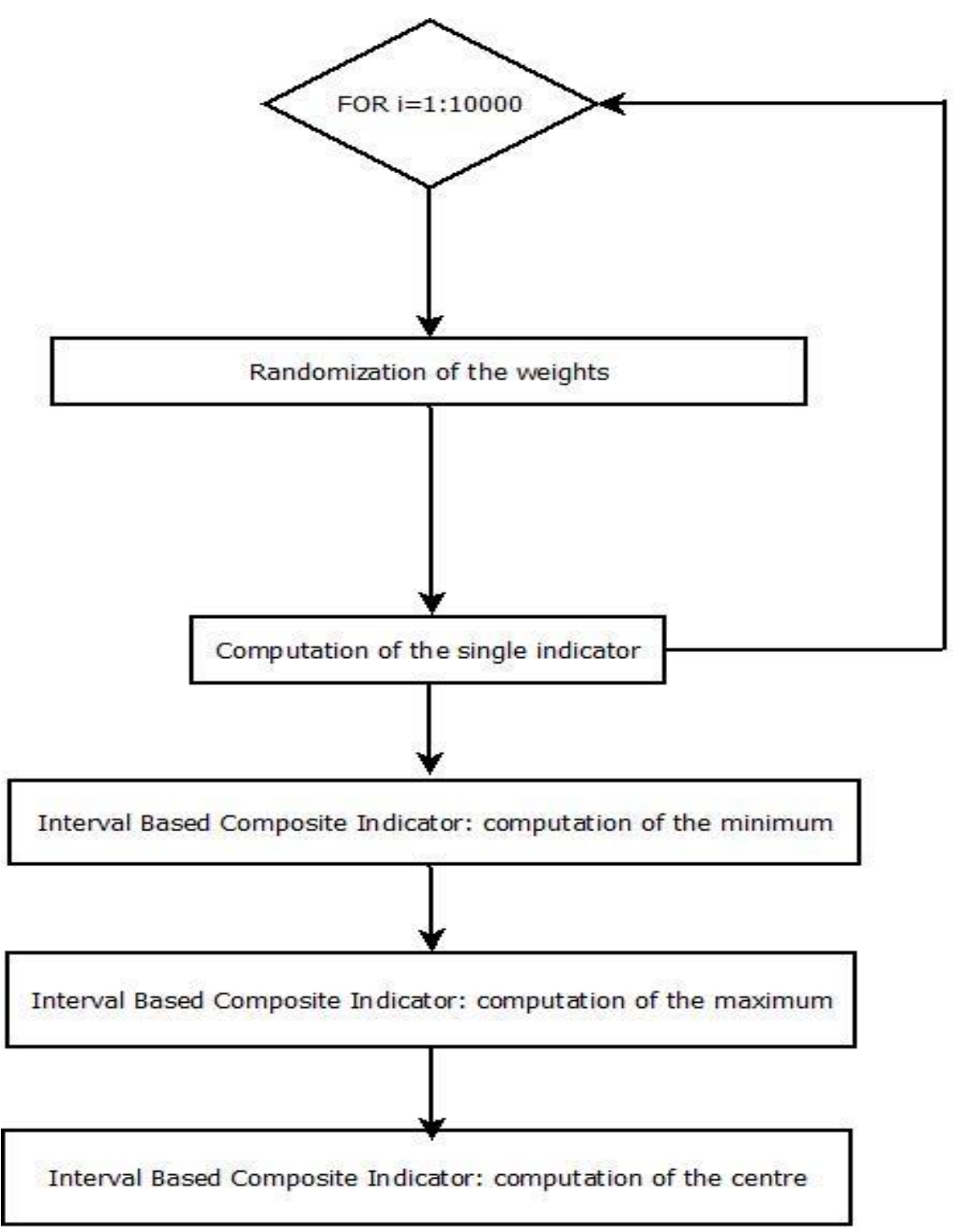

